\title{
PHYSICAL ACTIVITY AND FUNCTIONAL MOTOR SKILLS OF PRIMARY SCHOOL CHILDREN IN ESTONIA
}

\author{
LiIS SÜDA, KerLi MoOSES, ITI MÜÜRSEPP \\ Institute of Sport Sciences and Physiotherapy, University of Tartu, Tartu, Estonia
}

\begin{abstract}
The purpose of this study was to examine the physical activity (PA) and functional motor skills in 7-9-year-old children, and to find out whether participation in organized sport enhances their motor skills and fulfils the requirements for PA. To assess PA, all 38 participants (18 boys, 20 girls; mean age $8.1 \pm 0.7$ years) used accelerometer and accelerometer diary during one week. Average time per day spent in sedentary, light and moderate-to-vigorous physical activity (MVPA) was calculated. To measure motor skills, MABC-2 was used. Also, parental PA and educational level were recorded with questionnaire. PA of children was not associated with their motor skills ( $\mathrm{p}>0.05)$. Recommendations for daily PA were fulfilled by two children (5.3\%), seven children (18.4\%) did not meet the recommendations in any of the measured days. Both, boys and girls spent significantly more time in sedentary on schooldays than on weekend-days $(\mathrm{F}=23.122, \mathrm{p}<0.001)$. Organized sport participation was not associated ( $\mathrm{p}>0.05)$ with PA or motor skills. Also, parent and child PA were not significantly correlated. Average PA of children is lower than recommended. However, PA was not correlated with motor skills. The higher was parental educational level, the higher were motor skills of their child.
\end{abstract}

Keywords: accelerometry; health; physical fitness; children; motor skills

\section{INTRODUCTION}

Regular physical activity should be part of the everyday life of children as it promotes musculoskeletal, cardiovascular and neuromuscular development and helps to maintain healthy weight [34]. However, the physical activity of children is low [20] and level of overweight has increased that could lead to 
different health related risk factors in the future [1]. As physical inactivity is independently associated with growing cardiovascular disease risk [1], it is important to pay attention to healthy lifestyle and promote physical activity already at early age. In the order to avoid several health problems, at least 60 min of moderate-to-vigorous physical activity (MVPA) is recommended to 5-17-year-old children every day [34]. MVPA means physical activities that cause sweating and faster breathing at least in a small extent [17].

Although physical activity has several positive effects on child health, physical activity of children in European countries is low. For example, the recommendations for daily physical activity among 2-10-year-old children in 8 European countries was fulfilled on average by $2.0-14.7 \%$ of girls and by 9.5-34.1\% of boys [20]. Also, it has been shown in northern France that only a small proportion of children accumulate at least $60 \mathrm{~min}$ of recommended physical activity per day [2].

One key factor that can influence the participation in physical activity is the motor skills of children [14, 18, 21]. Stodden et al. [29] have argued that if the basic movement skills like running, jumping, throwing and catching are not well developed, it can reduce child's participation in physical activities, because he/she does not perceive positive achievement. Moreover, the association between motor skills and physical activity gets stronger as child gets older [29]. Also, the environmental and individual differences can determine the relationship between motor skills and physical activity children with higher motor skills have greater opportunities to take part in different physical activities, sports and games. It has been suggested that at that time, children with higher motor skills choose higher level of physical activities, but children with lower motor skills will stay on lower level of physical activity [29].

In primary school children, functional motor skills are important factors to determine participation in active play and physical activity [21]. For example, children who are not functionally limited may enjoy physical activity more likely and thus, engage in more regular practise of the fundamental movement patterns than children with poorer motor skills [9]. The same authors suggest that more skilful children engage in more regular practise of the fundamental movement patterns and thus become even more proficient and engage more in active play. Nevertheless, every kind of physical activity (e.g. running) does not necessarily promote development of functional motor skills (e.g. catching or throwing the ball) [26]. As stated by Kantomaa et al. [17] children who do not prefer participation in active play and who have motor problems, may benefit from interventions to promote physical activity and fitness later in life. 
Another aspect that can have influence on the physical activity levels and lifestyle of children, are the parents. A recent study showed a positive relationship between the higher educational level of parents and the physical activity of children [8]. Still, there is no consensus concerning the influence of parents' physical activity on child. As stated in one study, the higher MVPA level in parents is associated with higher MVPA level in children [13]. Moreover, in case both parents are physically very active, the physical activity of their child tended to be even higher. At the same time, others have found no association between parent and child physical activity status, while children with at least one parent physically active, attended more often to organized sport [10].

The purposes of this study were (a) to examine the associations between physical activity, participation in organized sports and functional motor skills in 7-9-year-old Estonian children, (b) to compare physical activity of children on school-days and on weekend-days, (c) to find out whether the educational level or physical activity of parents is associated with physical activity or motor skills of children.

\section{MATERIALS AND METHODS}

\section{Subjects}

The participants were 38 children aged 7-9 years, who were recruited from mainstream primary schools of Tartu, Estonia. Exclusion criteria were musculoskeletal injuries or diseases and all kind of disabilities that could limit physical activity or motor skills. Written informed consent was obtained from participants and their parents. Approval for this study was given by the Research Ethics Committee of the University of Tartu.

\section{Procedures}

Anthropometric measurements were conducted at school, using a portable stadiometer (Seca 213, USA; $\pm 0.1 \mathrm{~cm}$ ) and medical weigh (A\&D Instruments, Abington, UK; $\pm 0.1 \mathrm{~kg})$. BMI was calculated $\left(\mathrm{kg} / \mathrm{m}^{2}\right)$ and overweight was classified according to International Obesity Task force cut off points [3].

Physical activity was measured during 7 consecutive days using ActiGraph GT3X accelerometer (ActiGraph LLC, Pensacola, FL, USA) using 15-second epochs. All participants got verbal and written instructions how to use the accelerometer and to remove accelerometer during water activities (e.g. bathing and swimming), as well as during sport activities where it was uncomfortable (e.g. judo and wrestling). Device was fixed on the hip level with elastic belt. Children and/or their parents filled in accelerometer 
diary where they marked the time when child woke up and went to sleep, the participation in organized sport, the time and reason for not wearing the accelerometer. Children were asked to maintain their everyday physical activity. Evenson cut off points were used [30], where 0-100 counts per minute was referred as sedentary activity, 101-2295 counts per minute was light physical activity, and $\geq 2296$ counts per minute was MVPA. It has been shown that Evenson cut off points are the most suitable in measuring physical activity of children [30].

Functional motor skills were assessed with standardized Movement Assessment Battery for Children-2 (MABC-2). This is a valid instrument to evaluate children's fine and gross motor skills with 8 different tasks and in 3 different age groups: 3-6-year-olds, 7-10-year-olds and 11-16-yearolds [16]. In the present study, tasks for 7-10-year-old children were used. MABC-2 was administered in a private room at school.

All parents filled in a questionnaire about their educational level and habitual physical activity.

Collected physical activity data were downloaded and processed by program ActiLife (v6.11.2), also the average time per day spent in sedentary, light and MVPA was calculated. The period when accelerometer did not detect any movements during 20 min was classified as non-wear time. Children were included to the study when they had at least $600 \mathrm{~min}$ of recorded activity per day and they performed MABC-2 test. According to these criteria, 2 children were excluded from the study - one of them did not fulfil minimum requirements for recorded activity and one didn't perform MABC-2 during the period of study.

\section{Statistical analysis}

In statistical analysis, all three MABC-2 components as well as final results were used. Parents were divided in two groups according to their physical activity - parents who were physically active at least 2 times or less than 2 times per week (at least $30 \mathrm{~min}$ at a time). Statistical analysis was carried out with IBM SPSS Statistics (v20.0.0). For descriptive statistics, mean and standard deviation (SD) were calculated. Statistical differences between groups were analysed with Mann-Whitney U test or t-test. ANOVA was used to analyse the differences among group means. To compare the physical activity of children on school-days and weekend-days, repeated measures ANOVA was used. Pearson correlation allowed assessing a possible linear association between two continuous variables. Linear regression was used to control the influence of children age to the associations between continuous variables. Significance level was $\mathrm{p}<0.05$. 


\section{RESULTS}

Characteristics of the study sample are presented in Table 1 . The mean age of children was $8.1 \pm 0.7$ yrs and boys were significantly older than girls $(\mathrm{p}=0.003) .27$ children had normal weight, but 11 (6 boys and 5 girls) were overweight. Children accumulated on average $55.3 \pm 17.4 \mathrm{~min}$ of MVPA per day what is less than recommended. Only 2 children (5.3\%) were physically active according to the recommendations, while 7 children (18.4\%) did not meet the recommendations in any of the measured days. On school-days and weekend-days, physical activity of children differed significantly only in the section of sedentary activity (Table 2). Both, boys and girls, spent significantly more time sedentary on school-days than on weekend-days $(\mathrm{F}=23.122, \mathrm{p}<0.001)$, but differences in light physical activity and MVPA were not significant. Children who spent more time in MVPA on schooldays, did it also on weekend-days $(\mathrm{r}=0.581, \mathrm{p}<0.001)$. In total, $78.9 \%(\mathrm{n}=30)$ of children participated in organized sports. From those children who participated in sport, five (16.7\%) did not meet recommended physical activity level in any of the measured days. From eight children who did not participate in any organized sport, three (37.5\%) did not meet the recommendations for daily physical activity.

MABC-2 test results are shown in Table 3. Average standard score of the test was $10.7 \pm 3.4$ that refers to age-appropriate motor skills. There were significant differences between boys and girls in manual dexterity component $(\mathrm{p}<0.01)$, balance component $(\mathrm{p}<0.01)$ and final result $(\mathrm{p}<0.05)$, where girls performed better than boys. When this finding was controlled for the age and sex of the children, differences in components remained significant.

Table 1. Description of the participants (Mean \pm SD).

\begin{tabular}{lccc}
\hline Parameters & Boys & Girls & All \\
\cline { 2 - 4 } & $\mathrm{n}=\mathbf{1 8}$ & $\mathrm{n}=\mathbf{2 0}$ & $\mathrm{n}=\mathbf{3 8}$ \\
\hline Age (years) & $8.4 \pm 0.6^{* *}$ & $7.8 \pm 0.6$ & $8.1 \pm 0.7$ \\
\hline Body mass $(\mathrm{kg})$ & $33.8 \pm 7.9$ & $30.5 \pm 9.8$ & $32.1 \pm 8.9$ \\
\hline Height $(\mathrm{cm})$ & $136.0 \pm 8.0$ & $132.5 \pm 5.6$ & $134.2 \pm 7.0$ \\
\hline BMl $\left(\mathrm{kg} / \mathrm{m}^{2}\right)$ & $18.1 \pm 2.8$ & $17.2 \pm 4.3$ & $17.6 \pm 3.6$ \\
\hline
\end{tabular}

$\mathrm{BMI}$ - body mass index;

${ }^{* *} p<0.01$ compared to girls. 
Table 2. Physical activity data in minutes (Mean \pm SD).

\begin{tabular}{llccc}
\hline \multirow{4}{*}{$\begin{array}{l}\text { Physical } \\
\text { activity }\end{array}$} & \multicolumn{1}{c}{ Boys } & Girls & All \\
\cline { 2 - 5 } & Sedentary & $\mathbf{n}=\mathbf{1 8}$ & $\mathrm{n}=\mathbf{2 0}$ & $\mathrm{n}=\mathbf{3 8}$ \\
\cline { 2 - 5 } & Light & $277.2 \pm 58.9^{* * *}$ & $474.7 \pm 40.5^{* * * *}$ & $468.8 \pm 49.8^{* * *}$ \\
\cline { 2 - 5 } & MVPA & $58.5 \pm 19.6$ & $282.5 \pm 38.5$ & $280.0 \pm 41.2$ \\
\hline \multirow{3}{*}{ Weekend-day } & Sedentary & $425.9 \pm 65.5$ & $418.6 \pm 54.7$ & $422.1 \pm 59.4$ \\
\cline { 2 - 5 } & Light & $267.2 \pm 57.7$ & $275.5 \pm 58.3$ & $271.6 \pm 57.4$ \\
\cline { 2 - 5 } & MVPA & $52.2 \pm 25.4$ & $50.8 \pm 24.1$ & $55.3 \pm 17.4$ \\
\hline \multirow{3}{*}{ Whole week } & Sedentary & $451.6 \pm 55.9$ & $458.0 \pm 35.0$ & $455.0 \pm 45.5$ \\
\cline { 2 - 5 } & Light & $276.6 \pm 41.5$ & $280.6 \pm 39.2$ & $278.7 \pm 39.8$ \\
\cline { 2 - 5 } & MVPA & $57.3 \pm 18.6$ & $53.5 \pm 16.6$ & $55.3 \pm 17.4$ \\
\hline
\end{tabular}

MVPA - moderate-to-vigorous physical activity;

*** $p<0.001$ compared to weekend-day.

Table 3. MABC-2 test results (Mean $\pm S D$ ).

\begin{tabular}{lccccc}
\hline & & $\begin{array}{c}\text { Manual } \\
\text { dexterity }\end{array}$ & $\begin{array}{c}\text { Aiming and } \\
\text { catching }\end{array}$ & Balance & Final result \\
\hline & S & $27.4 \pm 6.6^{* * \#}$ & $20.2 \pm 4.8$ & $27.0 \pm 9.6^{* * \#}$ & $74.6 \pm 16.8^{*}$ \\
\cline { 2 - 6 } $\begin{array}{l}\text { Boys } \\
\mathrm{n}=18\end{array}$ & $\mathrm{SS}$ & $9.3 \pm 2.8^{* * \#}$ & $10.5 \pm 2.9$ & $9.3 \pm 4.4^{* * \#}$ & $9.3 \pm 3.5^{*}$ \\
\cline { 2 - 6 } & $\mathrm{P}$ & $44.6 \pm 8.6^{* * \#}$ & $52.9 \pm 24.9$ & $46.3 \pm 38.4^{* * \#}$ & $44.8 \pm 33.2^{*}$ \\
\hline & $\mathrm{S}$ & $34.1 \pm 4.7$ & $18.6 \pm 3.4$ & $34.7 \pm 4.6$ & $86.3 \pm 10.6$ \\
\cline { 2 - 6 } Girls & $\mathrm{SS}$ & $12.6 \pm 2.6$ & $9.5 \pm 2.0$ & $13.2 \pm 3.0$ & $12.0 \pm 2.9$ \\
\cline { 2 - 6 }$=20$ & $\mathrm{P}$ & $74.0 \pm 20.6$ & $44.3 \pm 22.1$ & $78.3 \pm 28.5$ & $68.6 \pm 25.8$ \\
\hline All & $\mathrm{S}$ & $30.9 \pm 6.5$ & $19.3 \pm 4.1$ & $31.0 \pm 8.3$ & $80.7 \pm 15.0$ \\
\cline { 2 - 6 } $\mathrm{n}=38$ & $\mathrm{SS}$ & $11.1 \pm 3.1$ & $10.0 \pm 2.5$ & $11.3 \pm 4.2$ & $10.7 \pm 3.4$ \\
\cline { 2 - 6 } & $\mathrm{P}$ & $60.1 \pm 28.5$ & $48.4 \pm 23.6$ & $63.1 \pm 36.7$ & $57.3 \pm 31.5$ \\
\hline
\end{tabular}

$\mathrm{S}$ - score, SS - standard score, $\mathrm{P}$ - percentile;

${ }^{*} p<0.05$ compared to girls; ${ }^{* *} p<0.01$ compared to girls;

$\# p<0.05$ differences remained after controlling for the age of children. 
Educational level and physical activity data were obtained from 54 parents (females $n=27$; males $n=27$ ). Twenty-three mothers and 18 fathers had higher education (75.9\% of parents). Thirty-one parents (16 mothers, 15 fathers) were physically active at least 2 times per week ( $>30 \mathrm{~min}$ at a time). Twenty-three parents ( 12 mothers, 11 fathers) were physically active less than twice a week.

There were no associations between physical activity and functional motor skills in measured children ( $\mathrm{p}>0.05)$. Higher BMI in children was negatively correlated with balance component scores $(\mathrm{r}=-0.351, \mathrm{p}=0.033)$, while BMI was not significantly associated with the physical activity of children $(p>0.05)$. Participation in organized sports was not associated with physical activity or motor skills of the children, either with educational level or physical activity of parents ( $p>0.05)$. However, educational level of parents was significantly associated with better final results of the children in MABC- $2(\mathrm{~F}=4.208, \mathrm{p}=0.050$ and $\mathrm{F}=4.828, \mathrm{p}=0.037$ respectively). When both parents had higher education, child had even better results in the MABC-2 compared to children, whose parents had lower educational level ( $\mathrm{F}=5.506$, $\mathrm{p}=0.027$ ). Finally, lower physical activity of mothers was associated with better MABC-2 result ( $\mathrm{F}=4.735, \mathrm{p}=0.039)$ of a child. However, there were no significant associations between physical activity of parents and children.

\section{DISCUSSION}

According to this study, physical activity and functional motor skills were not associated in primary school children. These results are in accordance with Stodden et al. [29], who suggested that associations between physical activity and functional motor skills would be more pronounced in elementary school children than primary school children [29]. Additionally, Raudsepp and Päll [27] found that motor skills of the elementary school students where were not associated with their general physical activity, but with activities that require skill-specific physical activity. It is possible that modern trainings for children have become more skill-specific, so they do not influence the development of basic functional motors skills to the desired extent. However, several other studies have shown that children who have higher level of motor skills tend to be also more physically active [12, 21, 35]. Wrotniak et al. [35] found that motor skills of 8-10-year-old children are positively correlated to MVPA and negatively to their sedentary time.

In our study only very small proportion of children fulfilled the recommended physical activity level. When interpreting different study results, it should be taken into consideration that the number of children compliant 
with physical activity recommendations is influenced by different physical activity cut off points $[2,15]$. Therefore, it is difficult to compare studies with different cut off points.

In the present study, the physical activity level of children on schooldays and on weekend-days was similar. However, during the school-days children were more sedentary compared to the weekend-days. Our study is not in line with previous ones, where children are physically more active on school-days compared to weekend-days $[19,23,25]$. Nevertheless, the physical activity of children is low and therefore more attention should be paid to raising the physical activity level of children on both school-days and weekend- days.

One possible explanation why the physical activity level of children was lower than expected is that our measurements took place during winter. In winter time in Estonia the daylight time is relatively short and temperature low. Kolle et al. [19] have found that 9-year-old children are 3.3 times more likely to meet recommended level of physical activity in spring time than in winter. Also, Mattocks et al. [22] have suggested that in countries where seasons are very different, physical activity can be more influenced by daylight time, rainfall and temperatures.

We found that BMI of the children is an important factor that influences the results in MABC-2 balance subtest. Also, Faught et al [11] had shown that the relative body fat influences negatively children's postural control. Authors suggested that it should be taken into consideration while interpreting MABC-2 test results.

In current research, the higher educational level of parents was positively associated with better functional motor skills of children. Also Cools et al. [4] showed similar results in their research, where parental educational level was positively associated with the motor skills of their children. Thus, we can conclude that parental educational level is a predicting factor of their child's motor skills. Therefore, it is important to raise awareness about the importance of physical activity and healthy lifestyle of children amongst parents with lower educational levels. It is more likely that highly educated parents find the relevant information by themselves, but others may need more outreach and awareness from different institutions. In addition, the present study showed that children whose mothers were less physically active, had better results in MABC-2 test. One possible explanation could be that if the mother does not participate in sport activities by herself, she might have more time to play with their child or to promote their attendance to different extracurricular activities that enhances the development of motor skills. Trost et al. [33] have pointed out that parents can support physical 
activity of children by transporting them to the sports centre, observing their activity and encouraging them. It has been suggested that parents' supportive activity may be more important than their positive example in promoting the physical activity of their children [10].

It has been found that participation in organized sport in children is associated with higher physical activity [10] and higher educational level [5] of parents. In the present study the participation in organized sport in children was not associated with any other measured parameters. It is possible that primary school children had been participating in organized sport for a too short time and it had not influenced their motor skills yet. However, it has been shown that children who had higher level of motor skills, spent more time engaged with sportive activities [24]. Additionally, Trost et al. [32] revealed that children were more active in free play than in organized sport lessons. Thus, participating in organized sport can be associated with better motor skills in children, but it is also possible that physical activity level is higher during active play than during physical training.

Physical activity and functional motor skills are not related in 7-9-yearold primary school children. The physical activity of children is lower than recommended and they are more sedentary on school-days than on weekend-days. There are no significant differences between the physical activity levels in boys compared to girls. Participation in organized sport is not related to physical activity level or motor skills of the children. Parental influence can be an important factor in enhancing motor skills development, because children who had at least one parent with higher education had also better results in the test of functional motor skills.

One of the limitations of current study was relatively small sample size. Also, despite of being valid method in measuring physical activity of children, the accelerometer has some limitations. For example, it has to be removed for water activities (e.g. bathing, swimming) and can therefore cause underestimation of physical activity $[23,30]$. In addition, during cycling $[28]$ and skating $[6,28]$ the accelerometers underestimate activity level because of minimal vertical displacement of the body. According to accelerometer diary, 5 bicycle trainings and 7 skating trainings might have been underestimated regarding physical activity. Also, activity of 16 swimming trainings and 5 wrestling trainings (for safety purpose) was not recorded. Moreover, the other limitation when using the accelerometer is the fact that child knows he/she is being monitored and could change his/ her usual physical activity [7].

Despite of limitations there are also strengths in this study. The main strength is that accelerometry is objective method to measure physical 
activity of children [31]. Moreover, when other studies have used 30- [2] or $60-[13,28]$ s intervals to record physical activity data, we used 15 -s intervals. Shorter intervals are more accurate in measurement of physical activity in children, because MVPA activities in children usually do not last longer than one minute [28]. In addition, also parents were included in our study to evaluate wider range of factors that could influence physical activity and motor skills of the children.

\section{ACKNOWLEDGEMENTS}

We are very grateful to the subjects who participated in this study.

\section{REFERENCES}

1. Andersen LB, Anderssen SA, Sardinha L, Froberg K, Riddoch CJ, Page AS. (2008) Fitness, fatness and clustering of cardiovascular risk factors in children from Denmark, Estonia and Portugal: The European Youth Heart Study. Int J Pediatr Obes, 3: 58-66.

2. Apété GK, Zitouni D, Hubert H, Guinhouya BC. (2012) Compliance of children in northern France with physical activity recommendations. Perspect Public Health, 132: 81-88.

3. Cole TJ, Bellizzi MC, Flegal KM, Dietz WH. (2000) Establishing a standard definition for child overweight and obesity worldwide: International Survey. BMJ, 320, 1240-1243.

4. Cools W, de Kristine M, Samaey C, Andries C. (2011) Fundamental movement skill performance of preschool children in relation to family context. J Sports Sci, 29: 649-660.

5. Cvetković N, Nikolić D, Pavlović L, Djordjević N, Olubović M. (2014) The socio-economic status of parents and their children's sports engagement. FU Phys Ed Sport, 12: 179-190.

6. Dencker M, Andersen LB. (2008) Health-related aspects of objectively measured daily physical activity in children. Clin Physiol Funct Imaging, 28: 133-144.

7. Dencker M, Thorsson O, Karlsson MK, Lindén C, Svensson J, Wollmer P, Andersen LB. (2006) Daily physical activity in Swedish children aged 8-11 years. Scand J Med Sci Sports, 16: 252-257.

8. Drenowatz C, Eisenmann JC, Pfeiffer KA, Welk G, Heelan K, Gentile D, Walsh D. (2010) Influence of socio-economic status on habitual physical activity and sedentary behavior in 8- to 11-year old children. BMC Public Health, 10: 214.

9. Duncan MJ, Stanley M. (2012) Functional movement is negatively associated with weight status and positively associated with physical activity in British primary school children. J Obes, 2012: 697563. 
10. Erkelenz N, Kobel S, Kettner S, Drenowatz C, Steinacker JM. (2014) Parental activity as influence on children's BMI percentiles and physical activity. J Sports Sci Med, 13: 645-650.

11. Faught BE, Demetriades S, Hay J, Cairney J. (2013) Does relative body fat influence the Movement ABC-2 assessment in children with and without developmental coordination disorder? Res Dev Disabil, 34: 4433-4438.

12. Fisher A, Reilly JJ, Kelly LA, Montgomery C, Williamson A, Paton JY, Grant S. (2005) Fundamental movement skills and habitual physical activity in young children. Med Sci Sports Exerc, 37: 684-688.

13. Fuemmeler, B. F., Anderson, C. B., \& Mâsse, L. C. (2011) Parent-child relationship of directly measured physical activity. Int J Behav Nutr Phys Act, 8: 17.

14. Gabbard CP. (2012) Lifelong motor development. 6th ed. Boston: Pearson Benjamin Cummings.

15. Guinhouya BC, Samouda H, de Beaufort C. (2013) Review paper: Level of physical activity among children and adolescents in Europe: a review of physical activity assessed objectively by accelerometry. Public Health, 127: 301-311.

16. Henderson SE, Sugden DA, Barnett AL. (2007) Movement assessment battery for children-2. 2nd ed. Examiner's manual. London: Pearson Assessment.

17. Kantomaa MT, Purtsi J, Taanila AM, Remes J, Viholainen H, Rintala P, Ahonen T, Tammelin TH. (2011) Suspected motor problems and low preference for active play in childhood are associated with physical inactivity and low fitness in adolescence. Plos One, 6: 1-8.

18. Kokštejn J, Psotta R, Frýbort P. (2012) Relationships between levels of motor coordination, attention and physical activity in children: The mediation model. Acta Univ Palacki Olomuc Gymn, 42: 29-40.

19. Kolle E, Steene-Johannessen J, Andersen LB, Anderssen SA. (2009) Seasonal variation in objectively assessed physical activity among children and adolescents in Norway: a cross-sectional study. Int J Behav Nutr Phys Act, 6: 36-44.

20. Konstabel K, Veidebaum T, Verbestel V, Moreno LA, Bammann K, Tornaritis M, Eiben G, Molnár D, Siani A, Sprengeler O, Wirsik N, Ahrens W, Pitsiladis Y; IDEFICS consortium. (2014) Objectively measured physical activity in European children: the IDEFICS study. Int J Obes, 38: 135-143.

21. Laukkanen A, Pesola A, Havu M, Finni T, Sääkslahti A. (2014) Relationship between habitual physical activity and gross motor skills is multifaceted in 5- to 8-year-old children. Scand J Med Sci Sports, 24: e102-e110.

22. Mattocks C, Leary S, Ness A, Deere K, Saunders J, Kirkby J, Blair SN, Tilling K, Riddoch C. (2007) Intraindividual variation of objectively measured physical activity in children. Med Sci Sports Exerc, 39: 622-629.

23. Nilsson A, Anderssen SA, Andersen LB, Froberg K, Riddoch C, Sardinha LB, Ekelund U. (2009) Between- and within-day variability in physical activity and inactivity in 9- and 15-year-old European children. Scand J Med Sci Sports, 19: 10-18.

24. Okely AD, Booth ML, Patterson JW. (2001) Relationship of physical activity to fundamental movement skills among adolescents. Med Sci Sports Exerc, 33: 1899-1904. 
25. O’Neill JR, Williams HG, Pfeiffer KA, Dowda M, McIver KL, Brown WH, Pate RR. (2014) Young children's motor skill performance: Relationships with activity types and parent perception of athletic competence. J Sci Med Sport, 17: 607-610.

26. Ortega B, Konstabel K, Pasqualis E, Ruiz JR, Hurtig-Wennlöf A, Mäestu J, Löf M, Harro J, Bellocco R, Labayen I, Veidebaum T, Sjöström M. (2013) Objectively measured physical activity and sedentary time during childhood, adolescence and young adulthood: a cohort study. Plos One, 8: e60871.

27. Raudsepp L, Päll P. (2006) The relationship between fundamental motor skills and outside-school physical activity of elementary school children. Pediatr Exerc Sci, 18: 426-435.

28. Riddoch CJ, Andersen LB, Wedderkopp N, Harro M, Klasson-Heggebo L, Sardinha, LB, Cooper AR, Ekelund U. (2004) Physical activity levels and patterns of 9- and 15-yr-old European children. Med Sci Sports Exerc, 36: 86-92.

29. Stodden DF, Goodway JD, Langendorfer SJ, Roberton MA, Rudisill ME, Garcia C, Garcia LE. (2008) A developmental perspective on the role of motor skill competence in physical activity: An emergent relationship. Quest, 60: 290-306.

30. Trost SG, Loprinzi PD, Senso M., Pfeiffer KA. (2009) Comparison of accelerometer cut-points for predicting physical activity intensity in youth. Med Sci Sports Exerc, 41: 173-173.

31. Trost SG, Pate RR, Freedson PS, Sallis JF, Taylor WC. (2000) Using objective physical activity measures with youth: how many days of monitoring are needed? Med Sci Sports Exerc, 32: 426-431.

32. Trost SG, Rosenkranz RR, Dzewaltowski D. (2008) Physical activity levels among children attending after-school programs. Med Sci Sports Exerc, 40: 622-629.

33. Trost SG, Sallis JF, Pate RR, Freedson PS, Taylor WC, Dowda M. (2003) Research article: Evaluating a model of parental influence on youth physical activity. Am J Prev Med, 25: 277-282.

34. WHO (World Health Organization). (2011) Global recommendations on physical activity for health. Recommended levels of physical activity for children aged 5-17 years.

35. Wrotniak BH, Epstein LH, Dorn JM, Jones KE, Kondilis VA. (2006) The relationship between motor proficiency and physical activity in children. Pediatrics, 118: 1758-1765.

\section{Correspondence to:}

Iti Müürsepp

University of Tartu, Institute of Sport Sciences and Physiotherapy

Jakobi 5-305, 51014, Tartu, Estonia

Tel: +3725135743

E-mail: iti.muursepp@ut.ee 